\title{
Bismuth nanoparticles obtained by a facile synthesis method exhibit antimicrobial activity against Staphylococcus aureus and Candida albicans
}

\author{
Roberto Vazquez-Munoz ${ }^{1 *}$ (D) M. Josefina Arellano-Jimenez ${ }^{2}$ (D) and Jose L. Lopez-Ribot ${ }^{1}$ (B)
}

\begin{abstract}
Background: Bismuth compounds are known for their activity against multiple microorganisms; yet, the antibiotic properties of bismuth nanoparticles (BiNPs) remain poorly explored. The objective of this work is to further the research of BiNPs for nanomedicine-related applications. Stable Polyvinylpyrrolidone (PVP)-coated BiNPs were produced by a chemical reduction process, in less than $30 \mathrm{~min}$.

Results: We produced stable, small, spheroid PVP-coated BiNPs with a crystalline organization. The PVP-BiNPs showed potent antibacterial activity against the pathogenic bacterium Staphylococcus aureus and antifungal activity against the opportunistic pathogenic yeast Candida albicans, both under planktonic and biofilm growing conditions.

Conclusions: Our results indicate that BiNPs represent promising antimicrobial nanomaterials, and this facile synthetic method may allow for further investigation of their activity against a variety of pathogenic microorganisms.
\end{abstract}

Keywords: Nanoantibiotics, Bismuth nanoparticles, Biofilms, Antimicrobial nanomaterials, Bacteria, Fungi

\section{Background}

Bismuth (symbol: $\mathrm{Bi}, \mathrm{Z}=83, \mathrm{~A}=208.98$ ) is a metallic element, non-toxic for humans (Lethal Intake $>5-20 \mathrm{~g} /$ day/Kg, for years) [1, 2]. Bismuth is insoluble in water but soluble in some organic solutions. The water-solubility and lipophilicity of bismuth can be enhanced when it is complexed with lipophilic molecules [3] and its biocompatibility is increased when it is chelated with hydroxyl or sulfhydryl groups. Bismuth compounds have been used in medicine for more than two centuries [4]. Bismuth subsalicylate has been utilized to treat diarrhea-related ailments since the 1900s [5], and most recently, bismuth

\footnotetext{
* Correspondence: roberto.vazquezmunoz@utsa.edu

${ }^{1}$ The University of Texas at San Antonio, San Antonio, TX 78249, USA

Full list of author information is available at the end of the article
}

compounds have been used in computed tomography imaging and anti-cancer therapy [6, 7]. In the U.S., around $30 \%$ of the bismuth compounds are used for cosmetic and pharmaceutical applications [4].

Several bismuth compounds display antibacterial and antifungal activity $[8,9]$ and can outperform the inhibitory activity of conventional antibiotics [10]. When bismuth is thiolated, such as in the case of bismuth-thiols (BTs) complexes, its antimicrobial activity is further enhanced [11]. Bismuth-dimercaptopropanol (bismuth-BAL) and other BTs display anti-biofilm activity [12]. Additionally, the thiolation of bismuth complexes increases their stability [13]; however, BTs stability is still relatively low when compared to other antimicrobial agents [14].

(c) The Author(s). 2020 Open Access This article is licensed under a Creative Commons Attribution 4.0 International License, which permits use, sharing, adaptation, distribution and reproduction in any medium or format, as long as you give appropriate credit to the original author(s) and the source, provide a link to the Creative Commons licence, and indicate if changes were made. The images or other third party material in this article are included in the article's Creative Commons licence, unless indicated otherwise in a credit line to the material. If material is not included in the article's Creative Commons licence and your intended use is not permitted by statutory regulation or exceeds the permitted use, you will need to obtain permission directly from the copyright holder. To view a copy of this licence, visit http://creativecommons.org/licenses/by/4.0/ The Creative Commons Public Domain Dedication waiver (http://creativecommons.org/publicdomain/zero/1.0/) applies to the data made available in this article, unless otherwise stated in a credit line to the data. 
The stability and antimicrobial activity of bismuth can be improved using nanotechnological approaches, as the detailed control of size, structure, and environment define the structural and physicochemical traits of nanostructures. Phan et al suggested that nanomaterials may display greater stability than their precursors under some specific conditions [15]. Also, the capping agents provide stability to nanoparticles [16]. Stability is critical for controlling the BTs potential toxicity [17] and for extending their shelf-life. In the last two decades, metallic elements with known -or potential- antimicrobial properties (silver, copper, and titanium, among others) have been used for synthesizing antimicrobial nanomaterials (nanoantibiotics) $[18,19]$.

Although some nanoantibiotics have been successfully transitioned to the market $[20,21]$, some promising metallic elements, such as bismuth, remain underresearched, even though some early reports indicate that bismuth nanoparticles (BiNPs) display promising antimicrobial activity on bacteria, fungi, and protozoan [3, 22]. A recent review from Shahbazi et al. [23], describes the diverse biomedical applications of bismuth compounds, including the antimicrobial properties of bismuth-based nanoparticles. According to Web of Science, 300 studies on BiNPs have been published in the last 20 years, yet only 12 are related to their antimicrobial activity (Fig. 1). This scarceness on research may be due to the difficulties in synthesizing BiNPs and their low stability under culture conditions.

Most of the current protocols for synthesizing biologically suitable BiNPs cannot be replicated in nonspecialized laboratories. Some methods require specialized equipment, such as gamma irradiators [24], laser ablation [25]; or controlled conditions, such as inert atmosphere [26], vacuum [27], or high temperatures [28, 29]. Also, some protocols require a long-time synthesis [24], or several intermediate steps [30]. Although biosynthesis -green chemistry- has been explored, it is not easily replicable in non-specialized laboratories [31, 32]. In general, BiNPs obtained using the above-mentioned protocols display an aspect ratio close to 1; although polyhedral, rod-like, and triangular shapes have also been described, and their sizes range from $1.7 \mathrm{~nm}$ to $1000 \mathrm{~nm}$ $(1 \mu \mathrm{m})$. Most recently our group has described a method for the fast, facile, and inexpensive synthesis of BiNPs using a simple chemical reduction process, which results in the generation of small nanoparticles with an aspect ratio close to 1 . This novel methodology does not require the use of sophisticated equipment, is easy to replicate, and can be readily implemented in non-specialized laboratories [33]. The main objective of this work was to elucidate the antimicrobial activity of these easy-tosynthesize BiNPs against Staphylococcus aureus, a pathogenic bacterium, and Candida albicans, an opportunistic, dimorphic yeast; and in the process increasing the research on this new type of nanoantibiotics.

\section{Methods}

\section{Reagents and nanomaterials}

2,3-Bis(2-methoxy-4-nitro-5-sulfophenyl)-2H-tetrazo-

lium-5-carboxanilide salt (XTT), menadione, and phosphate Saline Buffer (PBS) from Sigma-Aldrich (MO). Osmium Tetroxide $\left(\mathrm{OsO}_{4}\right)$ and Glutaraldehyde from Ted Pella; and PrestoBlue ${ }^{\mathrm{Ta}}$ Cell Viability Reagent from InVitrogen. $1 \% \mathrm{OsO}_{4}$ and $2.5 \%$ glutaraldehyde solutions

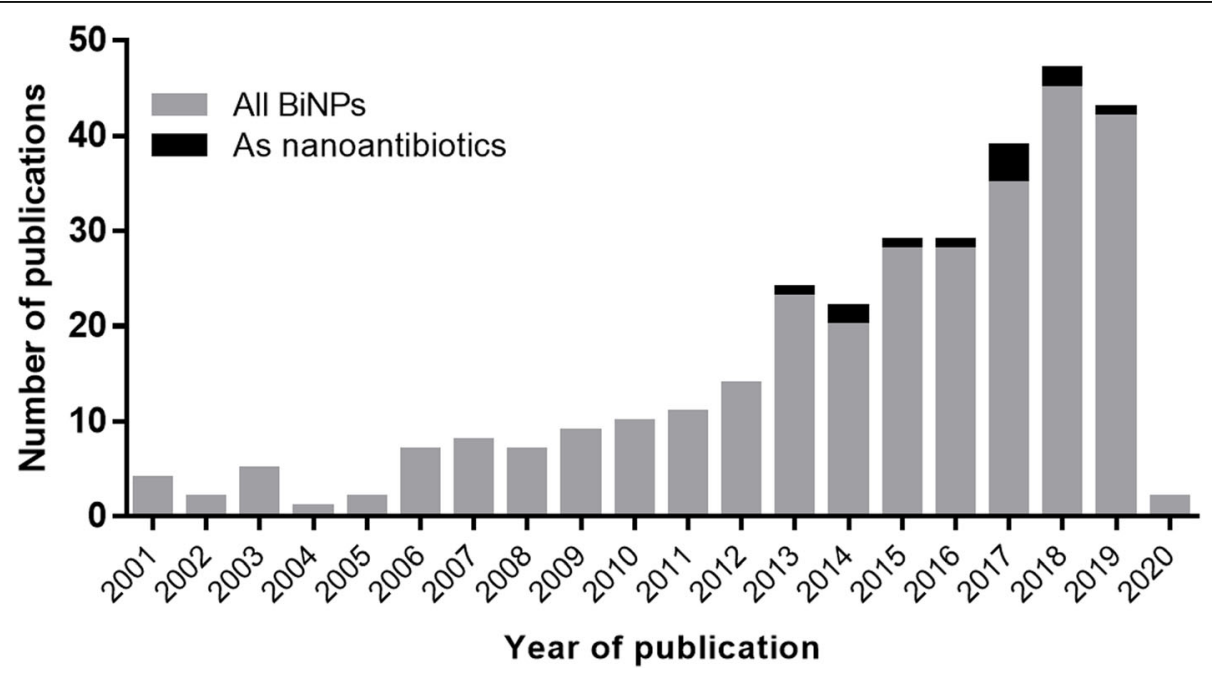

Fig. 1 Research of BiNPs in recent literature. BiNPs as antimicrobial agents remain barely researched. According to Web of Science, approximately 300 studies on BiNPs have been published in the last 20 years, from which only 12 are related to their antimicrobial activity. "The search parameter in the Web of Science (WoS) search was: "Bismuth nanoparticles" in title, abstract, and keywords. Then, the results were filtered by "antimicrobial" OR "antibacterial" OR and "antifungal"' 
were prepared in Milli Q water. A 10\% PrestoBlue solution was prepared in BPS.

\section{Nanoantibiotics}

PVP-coated bismuth nanoparticles were produced by an easy-to-synthesize chemical reduction protocol recently reported by our group [33]. Briefly, in a pre-warmed glycine solution, bismuth nitrate salts were added, and the $\mathrm{pH}$ was raised to 9. Then, BAL and PVP solutions were consecutively added to the bismuth solution. Finally, a $\mathrm{NaBH}_{4}$ solution was added, dropwise, in two batches three minutes apart from each other. The suspension was kept on vigorous stirring for $10 \mathrm{~min}$.

\section{Characterization of the PVP-BiNPs}

In a previous report, we demonstrated the presence and essential characteristics of the BiNPs, via Transmission Electron Microscopy and Energy Dispersive X-ray Spectroscopy, as well as the -potential via Dynamic Light Scattering Spectroscopy [33]. In this study, we expanded the characterization of the BiNPs to include different rounds of synthesis, as follows: High-Resolution Transmission Electron Microscopy (HR-TEM) for determining the single-particle structural lattice, using Selected-Area Electron Diffraction (SAED) analysis. The PVP-BiNPs, deposited on Type-B carbon-coated copper grids (Ted Pella Inc.), were examined in a JEOL 2010-F HR-TEM (Jeol Ltd.), with $200 \mathrm{kV}$ accelerating voltage. Dynamic Light Scattering analysis to determine the hydrodynamic size, using a Zetasizer Nano ZS (Malvern Panalytical). PVP-BiNPs were diluted in Milli $Q$ water and then transferred to a DTS1070 cell for the analysis. $U V$-Vis spectroscopy to follow the transition from bismuth (III) ions to the PVP-BiNPs, via the UV-Visible absorbance profile, in $10 \mathrm{~nm}$ steps, collected in a Genesys10 UV-Vis spectrophotometer (Thermo Fisher), from 200 to $600 \mathrm{~nm}$.

\section{Antimicrobial susceptibility assays Strains and culture conditions}

In this study, the Gram-positive bacterium USA200 methicillin-sensitive $S$. aureus (MSSA) UAMS-1 strain and the dimorphic yeast C. albicans strain SC5314 were used. For growth, S. aureus, inoculated in tryptic soy broth (TSB) (BD Difco, MD) and C. albicans, inoculated in Yeast extract Peptone Dextrose (YPD) broth, were incubated overnight in an orbital shaker at $35^{\circ} \mathrm{C}$. The antimicrobial activity of BiNPs was assessed in the planktonic and biofilm formation stages, as follows:

\section{BiNPs antimicrobial activity on the microbial planktonic cells}

We followed the CLSI guidelines to evaluate the susceptibility to the BiNPs, with slight modifications. For $S$. aureus the CLSI M07 [34] guidelines were followed; whereas for $C$. albicans the CLSI M27 [35] guidelines were used. Briefly, overnight microbial cultures were washed twice in PBS; adjusted for a final concentration of $10^{6}$ cells $\mathrm{mL}^{-1}$ in $\mathrm{MH}$ broth for S. aureus; and to $10^{3}$ cells $\mathrm{mL}^{-1}$, in RPMI culture media, for C. albicans. Then, $50 \mu \mathrm{L}$ of each microbial strain were transferred to 96-multiwell plates. Subsequently, bismuth compounds [BiNPs, bismuth-BAL and $\mathrm{Bi}\left(\mathrm{NO}_{3}\right)_{3}$ ] were prepared in a two-fold dilution series, for a final concentration range from 0.5 to $256 \mu \mathrm{g} \mathrm{mL}^{-1}$ (from $2.39 \mu \mathrm{M}$ to $1.22 \mathrm{mM}$ ), and $50 \mu \mathrm{L}$ were added to the multiwell plates with the microbial cells. Later, the multiwell plates were cultured at $180 \mathrm{rpm}$; at $37^{\circ} \mathrm{C}$ for $24 \mathrm{~h}$. The Minimal Inhibitory Concentration (MIC) was determined as the concentration at which no turbidity was detected.

\section{Assessment of the BiNPs antibiofilm activity on S. aureus}

The ability of the BiNPs to inhibit biofilm formation by $S$. aureus was evaluated following a protocol previously published by our group with minor modifications [36]. Briefly, a "biofilm broth" was prepared as follows: $45 \%$ Tryptic-Soy Broth (BD Difco, MD), 45\% Brain-Hearth Infusion broth (BD Difco, MD), and 10\% Bovine Fetal Serum (BD Difco, MD). Bacterial cells were washed twice in PBS and adjusted to $10^{8}$ cells $\mathrm{mL}^{-1}$ in the biofilm broth and transferred to the 96-multiwell plates. Bismuth compounds were prepared in a two-fold dilution series, in the biofilm broth, for a final concentration range from 0.5 to $256 \mu \mathrm{g} \mathrm{mL}^{-1}$ (from $2.39 \mu \mathrm{M}$ to 1.22 $\mathrm{mM}$ ) and transferred to the multiwell plates with $S$. aureus. The plates were cultured at $37^{\circ} \mathrm{C}$ for $24 \mathrm{~h}$. After the incubation time, the biofilms were washed with PBS and the Presto Blue ${ }^{\mathrm{Tm}}$ was added, and the multi-well plates were read spectrophotometrically as previously described by our group [37].

Assessment of the BiNPs antibiofilm activity on C. albicans The anticandidal activity of BiNPs, for preventing the biofilm formation, was evaluated using the methods previously reported by our group [38], with minor modifications. C. albicans cells from overnight cultures were washed in PBS, adjusted to $\times 10^{6}$ cells $\mathrm{mL}^{-1}$ in RPMI culture media, and transferred to the 96-multiwell plates. Then, BiNPs two-fold dilution series were prepared in RPMI, for a final concentration range from 0.5 to $256 \mu \mathrm{g} \mathrm{mL}^{-1}$, and transferred to the plates with C. albicans, and then cultured at $35^{\circ} \mathrm{C}$ for $24 \mathrm{~h}$. Postincubation, $C$. albicans biofilms were washed with PBS, then XTT/menadione was added. The absorbance of XTT was collected in a Benchmark Microplate Reader (Bio-Rad Inc), at $\lambda=490 \mathrm{~nm}$.

To generate the dose-response curves, the normalized results from the absorbance readings (from S. aureus 
and $C$. albicans) were fit to the variable slope Hill equation (for the nonlinear drug dose-response relationship) using Prism 8 (GraphPad Software Inc). Then, the BiNPs $\mathrm{IC}_{50}$ was calculated. The $\mathrm{IC}_{50}$ was established as the concentration of BiNPs that reduce the $50 \%$ of the bacterial growth. To ensure the reproducibility of the antimicrobial activity from the different rounds of BiNPs syntheses and the bismuth compounds, we used two biological replicates (multi-well plates) with two technical replicates within each plate.

\section{Ultrastructural analysis}

To assess the impact of the BiNPs on the biofilm structure and cell morphology of $S$. aureus and C. albicans, the samples were analyzed via Scanning Electron Microscopy (SEM). Briefly, BiNPs-treated and control (untreated) samples were washed with PBS, fixed with a $2 \%$ glutaraldehyde solution for $60 \mathrm{~min}$, and then stained and postfixed with a $1 \%$ Osmium tetroxide solution, for $30 \mathrm{~min}$ at $4{ }^{\circ} \mathrm{C}$. Next, samples were washed with PBS and dehydrated using an ascending concentration ethanol series, up to $100 \%$, and left to dry overnight. Finally, the samples were coated with gold in a Sputter Coater SC7620 (Quorum Technologies), for $25 \mathrm{~mA}$ for $3 \mathrm{~min}$. The gold-coated samples were observed in a TM4000Plus Scanning Electron Microscope (Hitachi Inc.), with a magnification 500 and $2500 x$, using a $10 \mathrm{KeV}$ voltage.

\section{Results and discussion}

\section{Characterization of the BAL-mediated PVP-BiNPs} High-resolution transmission electron microscopy (HR-TEM) In a previous report, HR-TEM revealed the morphology of the BiNPs [33]. For this work, an extended characterization via HR-TEM was performed in other rounds of syntheses. Our analyses revealed that the shape of the nanoparticles displayed an aspect ratio close to 1, although few specific shapes (i.e. polyhedrons) were observed (supplementary materials, Fig. s1). The average diameter of the nanoparticles is $8.4 \mathrm{~nm} \pm 6.7 \mathrm{~nm}$, ranging from $1.7 \mathrm{~nm}$ to $44.4 \mathrm{~nm}(n=1159)$ (supplementary materials, Fig. s1, inset). Approximately, $86.1 \%$ of the particle size was below $15 \mathrm{~nm}$. Some larger individual nanoparticles (50-100 nm) and clusters of nanoparticles were also observed. The cause of the formation of large individual nanoparticles and clusters may be due to the formation of "fast nucleation hotspots" where the $\mathrm{NaBH}_{4}$ is added into the solution.

The single-particle HR-TEM analysis revealed the crystallinity of the PVP-BiNPs. Lattice distance measurements agreed with reported low-index planes for crystalline $\mathrm{Bi}$ with cubic, hexagonal, and orthorhombic cell. The crystalline lattice depicted in Fig. 2a shows distances of $0.289,0.253$, and $0.246 \mathrm{~nm}$, which suggest an orthorhombic cell $(0.290 \mathrm{~nm}$ is the distance reported for the (2 1-1) plane in the orthorhombic cell) or misorientation. The SAED from the BAL-mediated PVP-BiNPs showed the appearance of a clear ring diffraction pattern, which confirmed the formation of crystalline bismuth nanostructures. Interestingly, the experimental d-spacing corroborates that BiNPs display a mixed arrangement, conformed by cubic and hexagonal phases. The $\mathrm{d}$-spacing for the cubic lattice were 2.68, 1.91, and $1.54 \AA$ (hkl 110, 200, and 211, respectively); whereas for the hexagonal lattice were $2.35,1.65$, and $1.44 \AA$ (hkl 104, 024, and 122, respectively) (Fig. 2b), according to the data from the standard powder diffraction cards of the Joint Committee on Powder Diffraction Standards (JCPDS), bismuth files numbers \#26-0214 (cubic phase), and \#44-1246 (hexagonal phase).

\section{Dynamic light scattering spectroscopy}

The PVP-BiNPs hydrodynamic size is $22.5 \pm 0.06 \mathrm{~nm}$. The hydrodynamic size is greater than the metal core size observed on TEM images $(22.5 \mathrm{~nm}$ vs $8.6 \mathrm{~nm}$ respectively). The increase in the hydrodynamic size may correspond to the $10 \mathrm{~K}$ PVP coating chain-like molecules, whose structures extend when hydrated under the aqueous environment. The PVP coating improves BiNPs
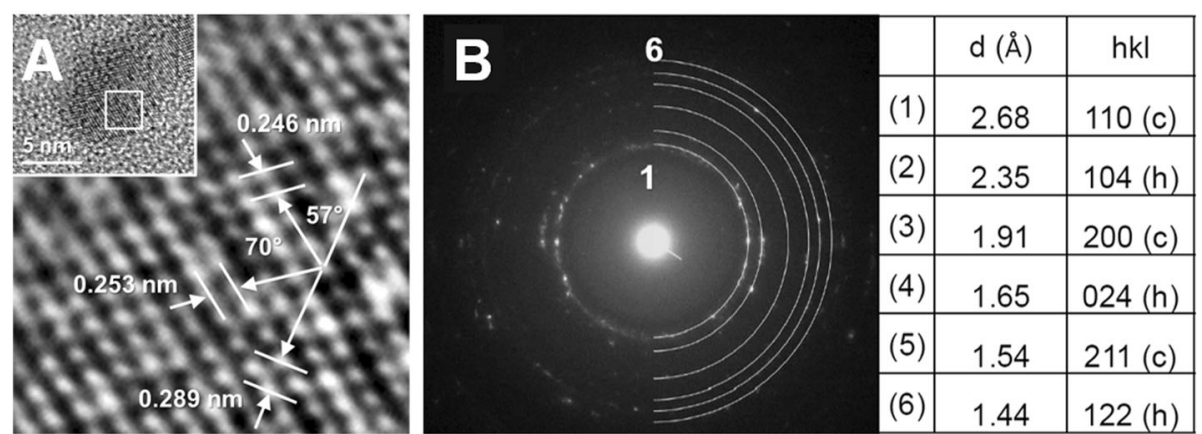

Fig. 2 Characterization of the BAL-mediated PVP-BiNPS. a Our HR-TEM analysis from a single particle confirms their crystalline organization, whereas the (b) Electron Diffraction Pattern reveals their crystalline lattice as a cubic and hexagonal organization 
stability. HR-TEM images reveal that BiNPs are individual structures; however, they may be clustering over time due to the interactions of the organic compounds in the suspension.

\section{UV-Vis characterization}

The bismuth compounds displayed distinct absorbance profiles. The bismuth (III) ions profile (diluted in glycine) displayed an absorbance profile with a maximum at $\lambda=240 \mathrm{~nm}$, whereas the bismuth-BAL complex displayed a decreasing profile with a flat absorbance profile, from $\lambda=340$ to $390 \mathrm{~nm}$, with a rapid decline $\lambda=400 \mathrm{~nm}$. In contrast, the BiNPs absorbance profile showed a surface plasmon with a shoulder at $\lambda=250 \mathrm{~nm}$, close to the reported by other authors [39], and a shoulder at $\lambda=$ $270 \mathrm{~nm}$. Also, a flat profile was observed at $\lambda=340$ with a decrease at $\lambda=380 \mathrm{~nm}$. The difference observed in the absorbance profiles demonstrates the chemical transition from the bismuth (III) ions to the bismuth-BAL complex and then to the bismuth nanoparticles (Fig. 3, bottom). As seen in nanoparticles from other elements, the absorbance profile is determined by the surface physicochemical traits of the nanoparticles, such as shape and size distribution and the capping agents, among others [40]. In contrast to the AgNPs, a "typical" UV-Vis absorbance profile for BiNPs has still not been suggested.
According to the literature, different bismuth nanoparticles exhibit spectra profiles with maximum peaks at bands in different locations, such as $\lambda=275 \mathrm{~nm}$ and $\lambda=$ $360 \mathrm{~nm}$ [41], $\lambda=281 \mathrm{~nm}$ [42], $253 \mathrm{~nm}$ [39], and $\lambda=313$ $\mathrm{nm}$ [43]. Ma et al reported that BiNPs with a size below $10 \mathrm{~nm}$ did not display a UV-Vis absorbance profile. However, our small BiNPs did show a profile (average size $<10 \mathrm{~nm}$ ), yet, the absorbance profile may be from the BiNPs larger than $10 \mathrm{~nm}$.

\section{Mechanism of BAL-mediated PVP-BiNPs synthesis}

We used the bottom-up methodology approach for producing the BAL-mediated synthesis of the PVP-BiNPs. In a previous work, we described the procedure for synthesizing the nanoparticles [33]. Here, we propose the potential interactions between the precursors, aiming to describe the mechanism that leads to the formation of the PVP-BiNPs. The water-insoluble bismuth nitrate readily dissolves in the glycine solution, allowing the release of bismuth (III) ions (Fig. 3, segment A), but the induction of an alkaline environment reduces the solubility of bismuth (III) ions. Yet, the alkaline environment allows dimercaptopropanol (BAL) to rapidly sequester the bismuth (III) ions, favoring the formation of the highly soluble bismuth-BAL complex (the solution changes from white to yellow, and the absorbance profile

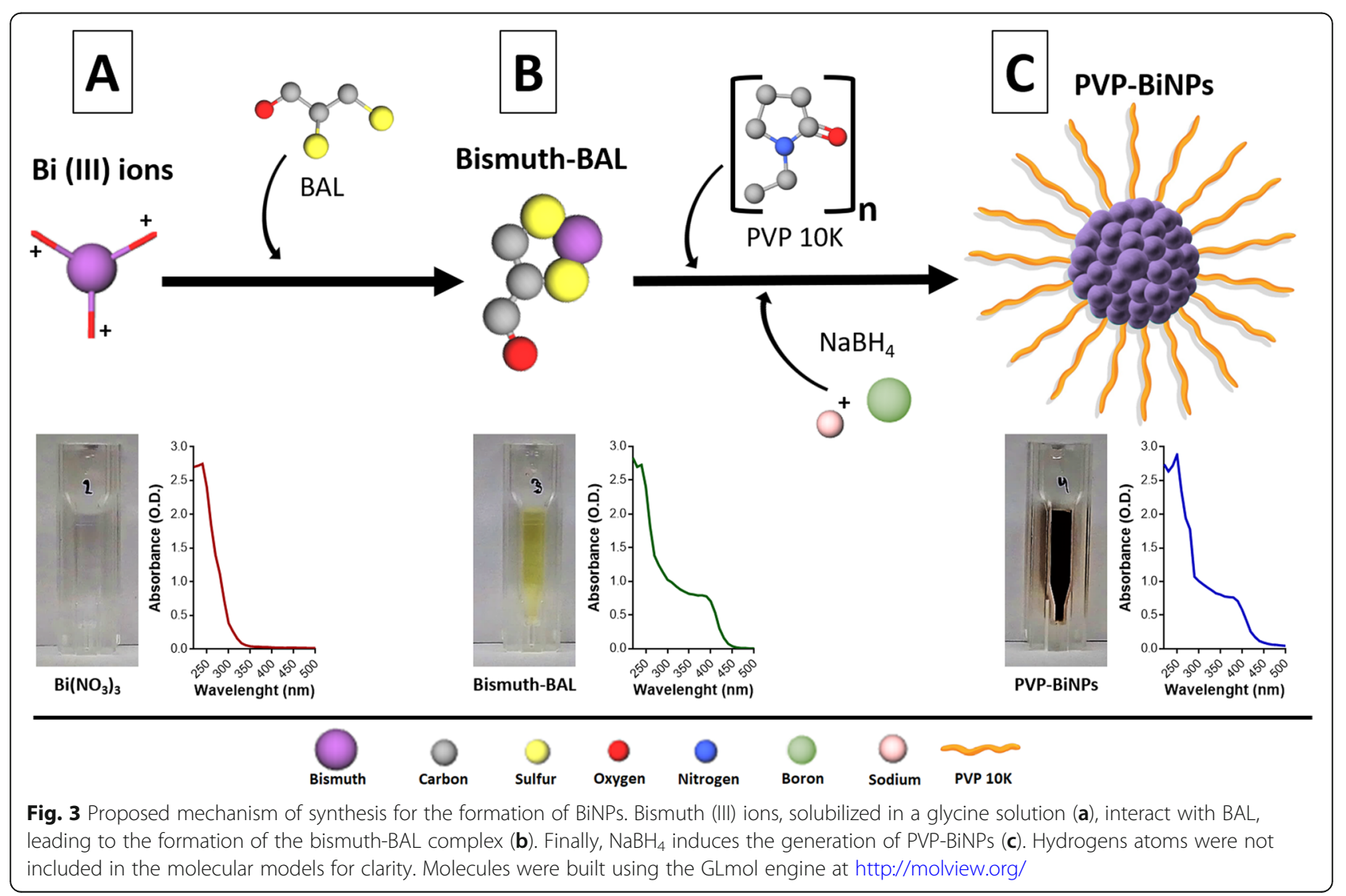


changes) (Fig. 3 segment B). PVP K-10 -a dispersant, mild reducing agent-, slowly initiates the formation of the nanoparticles, while regulates their size and shape. Moreover, PVP interacts chemically with bismuth [42], leading to the formation of a PVP coat on the nanoparticles. Although different biomolecules have been used as stabilizers for synthesizing BiNPs, such as starch [44]; PVP-K10 was selected due to the multiple properties that confer to the nanoparticles -negative charge, stability, and low toxicity- [45-47]. $\mathrm{NaBH}_{4}$-a strong reducing agent- speed up the synthesis process. The rapid formation of the BiNPs is revealed by the color change of the reacting mixture (from yellow to black), and by a final transition on the UV-Vis absorbance (Fig. 3 segment $\mathrm{C}$ ). The change of color to black is attributed to the increasing presence of -nanostructured- elemental bismuth, due to the shift of the oxidation state during the reduction of bismuth (III) ions [41]. The HR-TEM singleparticle analysis and the DLS spectroscopy confirm the formation of bismuth nanoparticles, tentatively coated by PVP, as the hydrodynamic diameter is larger than the metallic BiNPs diameter.

\section{Stability of the PVP-coated BiNPs}

The stability of bismuth nanoparticles in aqueous suspensions depends on several factors, such as $\mathrm{pH}$ [48], exposure to air [49], capping agent [50], and the bismuththiol bonding $[11,13]$. Thiolation increases the bismuth solubility and stability [13]; yet, the stability of bismuththiol complexes is still relatively low, as they remain in suspension for short periods [14]. Our synthesis method [33] enhances the BiNPs stability when compared with the bismuth (III) ions and the bismuth-BAL complex, under the same conditions of temperature, exposure to atmospheric air, and changes on $\mathrm{pH}$. Preparations of 15 $\mathrm{mM}$ bismuth nitrate and $15 \mathrm{mM}$ bismuth-BAL complex precipitated within a few days; in contrast, the BALmediated PVP-coated BiNPs are stable for at least 11 weeks (Fig.s2, supplementary materials). This increase in stability is an improvement over other processes for producing PVP-BiNPs, as it has been reported that PVPcoated BiNPs precipitate in less than 4days [50]; Also, some studies show that BiNPs in aqueous suspensions are rapidly dissolved if the $\mathrm{pH}$ is out of the $8-10$ range [48] or when exposed to air [51], yet our BiNPs remained stable for hours when dissolved in MilliQ water ( $\mathrm{pH} 7$ ) and when exposed to air. In our protocol, both solubility and stability of bismuth are increased due to the addition of BAL, leading to more stable BiNPs. The BAL-mediated synthesis of PVP-BiNPs kept the stability of nanoparticles even though the synthesis was performed under atmospheric air conditions.

Moreover, we tested variations on the synthesis method and found that PVP-BiNPs without BAL were unstable, precipitating in less than a week, whereas BiNPs without glycine or PVP were highly unstable, precipitating within minutes after the synthesis. These findings suggest that BiNPs stability is related to the bismuth (III) ions availability for the synthesis process (increased solubility) and capping molecules, with PVP acting as a capping/dispersant agent [47].

\section{BiNPs display antibacterial and antifungal activity on the} planktonic and biofilms stages

PVP-BiNPs display strong antimicrobial activity against the planktonic cells S. aureus and C. albicans (Fig. 4a). The BiNPs MIC against the planktonic cells of $S$. aureus was $1 \mu \mathrm{g} \mathrm{mL}^{-1}$. The antibacterial activity of these BiNPs is similar or better than the BiNPs activity reported before in the literature. Previously reported BiNPs MIC values ranged from $1.05 \mu \mathrm{g} \mathrm{mL}^{-1}$ for $S$. mutans and $S$. gordonii to $1500 \mu \mathrm{g} \mathrm{mL}^{-1}$ for the MRSA strain $[3,52]$. Also, the antimicrobial activity of the resulting BiNPs is similar or better than several antimicrobial drugs, such as Vancomycin or Oxacillin ( $\mathrm{MIC}=1.5 \mu \mathrm{g} \mathrm{mL}^{-1}$ ) and Ceftaroline $\left(\mathrm{MIC}=0.5 \mu \mathrm{g} \mathrm{mL}^{-1}\right)$ [53]. Likewise, the BiNPs antimicrobial activity outperforms the antibacterial activity of silver nanoparticles (AgNPs) $(\mathrm{MIC}=4 \mu \mathrm{g}$ $\mathrm{mL}^{-1}$ ) [54] and other metallic nanoparticles, such as copper $\left(\mathrm{MIC} \geq 28.6 \mu \mathrm{g} \mathrm{mL}^{-1}\right)$ or zinc $(\mathrm{MIC} \geq 85.8 \mu \mathrm{g}$ $\left.\mathrm{mL}^{-1}\right)$ [55].

For C. albicans, the BiNPs MIC was $16 \mu \mathrm{g} \mathrm{mL}^{-1}$. As far as the authors know, the antifungal activity of BiNPs has only been addressed in one other study, also against C. albicans, with a MIC equivalent to $2.09 \mu \mathrm{g} \mathrm{mL}^{-1}$ [3]. When compared with antifungals, the BiNPs antimicrobial activity for $C$. albicans is parallel to azole antifungal agents but less potent than amphotericin B or echinocandins $[56,57]$. In contrast to their antibacterial activity, the BiNPs antifungal activity seems to be lower when compared with AgNPs (MIC $=2 \mu \mathrm{g} \mathrm{mL}^{-1}$ ) [54]; however, they are more potent than other nanoantibiotics, such as copper nanoparticles $\left(\mathrm{MIC} \geq 150 \mu \mathrm{g} \mathrm{mL}^{-1}\right)$ [58].

The synthesized PVP-BiNPs were also capable of inhibiting biofilm formation by both $S$. aureus and C. albicans (Fig. $4 \mathrm{~b}$ ). In the case of $S$. aureus biofilms, the $\mathrm{IC}_{50}$ was $1.06 \mu \mathrm{g} \mathrm{mL}^{-1}$, which is among the most potent activity of BiNPs reported against the biofilm formation phase on bacteria. Baddidery et al reported that $2.61 \mu \mathrm{g}$ $\mathrm{mL}^{-1}$ prevents the cell attachment on a polycarbonate membrane [59]. In contrast, Dalvand showed that even concentrations of BiNPs as high as $1500 \mu \mathrm{g} \mathrm{mL}^{-1}$, inhibited the MRSA biofilms only by $16 \%$ [52]; Moreover, Hernandez-Delgadillo reported that a BiNPs concentration of $10,000 \mu \mathrm{g} \mathrm{mL}^{-1}$ was required to prevent the biofilm formation on Enterococcus faecalis [60]. BiNPs display better antibiofilm activity than silver nanoparticles $\left(\mathrm{IC}_{90}=15 \mu \mathrm{g} \mathrm{mL}^{-1}\right)$ [61]. When compared with 


\section{Planktonic stage}

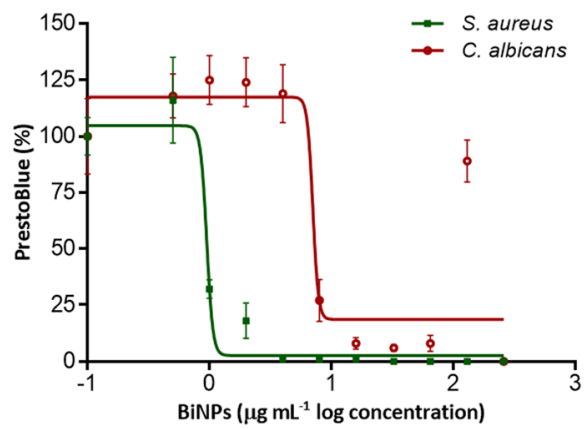

Biofilm formation stage

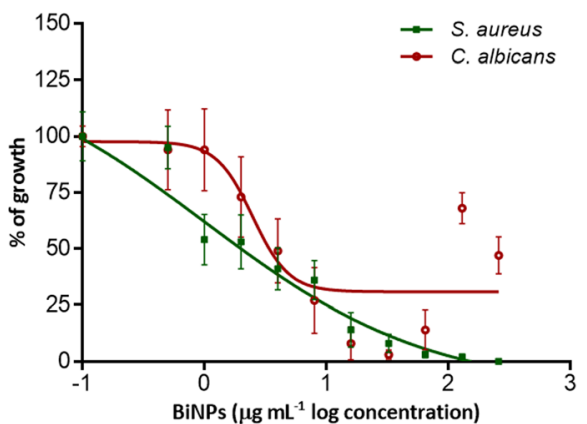

Fig. 4 Antimicrobial activity of the BiNPs. Dose-response curves of the BiNPs antimicrobial activity against the bacterium S. aureus and the yeast C. albicans. Planktonic cells (green line) and Biofilms formation stage (red lines)

antibacterial drugs, the BiNPs exhibit comparable antibiofilm activity to that of vancomycin $\left(\mathrm{IC}_{100}=2 \mu \mathrm{g}\right.$ $\left.\mathrm{mL}^{-1}\right)$ and linezolid $\left(\mathrm{IC}_{100}=4 \mu \mathrm{g} \mathrm{mL}^{-1}\right)$ [62].

Regarding C. albicans, the calculated $\mathrm{IC}_{50}$ value for BiNPs against biofilms formed by this fungus was $7.9 \mu \mathrm{g}$ $\mathrm{mL}^{-1}$, which interestingly is very close to its value under planktonic conditions As far as the authors know, the antibiofilm activity of BiNPs only has been addressed in one other study, where a concentration of $418 \mu \mathrm{g} \mathrm{mL} \mathrm{L}^{-1}$ was required to inhibit the C. albicans biofilm [63].. When compared with BiNPs, AgNPs display better antibiofilm activity $\left(\mathrm{IC}_{50}=0.089 \mu \mathrm{g} \mathrm{mL}^{-1}\right)$ [64]. The anticandidal activity of BiNPs, compared to antifungal agents, is better than Fluconazole $\left(\mathrm{IC}_{50}>1024 \mu \mathrm{g} \mathrm{mL}^{-1}\right)$, but lower than Amphotericin $\mathrm{B}\left(\mathrm{IC}_{50}>1 \mu \mathrm{g} \mathrm{mL}^{-1}\right)$ and the echinocandins $[65,66]$. In Table S1 (supplementary materials) the antimicrobial activity of our BiNPs is compared with other BiNPs reported in the literature, against the planktonic and biofilm stages in bacteria and fungi.

Moreover, the antibacterial effect of $\mathrm{Bi}\left(\mathrm{NO}_{3}\right)_{3}$ and the bismuth-BAL complex was assessed against the planktonic stage and during the biofilm formation phase of $S$. aureus and $C$. albicans. For $S$. aureus, the antibacterial activity of the bismuth-BAL complex equals that of the BiNPs. In contrast, bismuth (III) ions have the lowest performance. For C. albicans, BiNPs displayed the highest antifungal activity, followed by the bismuth (III) ions, whereas the bismuth-BAL complex exhibited the lowest activity. The activity of all bismuth compounds under planktonic and biofilm growing conditions is summarized in Table 1, whereas the corresponding doseresponse curves are in the supplementary materials section (Fig. s3). As suggested by Domenico et al [67], the bismuth-BAL complex displays better antimicrobial activity than the $\mathrm{Bi}\left(\mathrm{NO}_{3}\right)_{3}$ salts. The antibacterial activity of different bismuth compounds against the bacterial planktonic stage and biofilm has been reported by different groups $[8,12]$.
Furthermore, since the antimicrobial activity of BiNPs has been scarcely addressed, the mechanism of action has not been elucidated. Both BiNPs precursors -bismuth (III) ions and bismuth-BAL complex- display antimicrobial activity against both strains, therefore it is likely that the fundamental mechanisms of action of BiNPs are related to their precursors. The mechanisms of action of bismuth (III) ions are partially known. Ionic bismuth binds to glutathione, which improves its translocation inside of cells, from where it targets proteins and inhibit enzymes, such as urease and fumarase [68, 69]. Regarding the bismuth-BAL complex, the mechanisms related to their antimicrobial activity are not fully understood. However, it is known that bismuth-thiols increase the permeability of the bacterial cell membrane [70]. Also, in the case of S. epidermalis, bismuth-thiol complexes reduce the glycocalyx production on the capsules [67]. It is highly likely that BiNPs release bismuth (III) ions with antimicrobial activity; though, due to the evident difference in the antimicrobial activity between BiNPs and bismuth (III) ions, the nanostructured arrangement of the BiNPs must be playing an unknown key role for enhancing the activity. So far, the mode of action of the BiNPs remains to be uncovered.

Table 1 Antimicrobial activity of bismuth compounds ( $\mu \mathrm{g}$ $\mathrm{mL}^{-1}$ ) on the planktonic cells and biofilm stages of S. aureus

\begin{tabular}{llll}
\hline \multirow{2}{*}{$\begin{array}{l}\text { Phase/ } \\
\text { strain }\end{array}$} & \multicolumn{3}{l}{ Treatments Inhibitory concentration } \\
\cline { 2 - 4 } & BiNPs & Bismuth-BAL complex & Bismuth (III) ions \\
\hline Planktonic cells $^{\text {a }}$ & & 161.2 \\
S. aureus & 0.9 & 1.1 & 8 \\
C. albicans & 7 & 57.4 & \\
Biofilm formation & & & 31 \\
S. aureus & 1 & 2.1 & 8.5 \\
C. albicans & 2.5 & $>256$ & \\
\hline
\end{tabular}

${ }^{\text {a }}$ Minimal Inhibitory concentration (MIC)

${ }^{b}$ Calculated $\mathrm{IC}_{50}$ 
The BAL-mediated PVP-BiNPs alter the biofilm ultrastructure

Scanning Electron Microscopy confirmed that BiNPs hinder the $S$. aureus ability to form biofilms. Low magnification SEM Images revealed that untreated S. aureus samples form biofilms with dense groups of cells (Fig. 5a). High-magnification SEM images confirmed the presence of highly-packed multi-layered clusters of cells (Fig. 5d). The morphology of the S. aureus cells revealed that they do not display any evident variations on their shape and size. In contrast, in the treated samples with sub-lethal concentrations of BiNPs $\left(2 \mu \mathrm{g} \mathrm{m}^{-1}\right)$, the treated biofilms appeared to be less dense, but with a larger covered area (Fig. 5b). The high-magnification images showed that the biofilm display lower thickness, with less clustered bacterial cells. Interestingly, the bacterial cell morphology was altered by the BiNPs, as evidenced by the diversity of cellular sizes and shapes observed (Fig. 5e). This may be caused by the effects of bismuth on the cells, such as the denaturing of proteins $[68,69]$ and changes in the cell membrane permeability [70]. Other potential mechanisms remain to be further studied and elucidated. In samples treated with higher concentrations of BiNPs $\left(8 \mu \mathrm{g} \mathrm{mL}^{-1}\right)$, the biofilms formation was almost completely abolished. Some sparse, small clusters of bacterial cells were present (Fig. 5c), with most of the observed cells displaying similar shape and size, with the exception of a few larger cells (Fig. 5f).
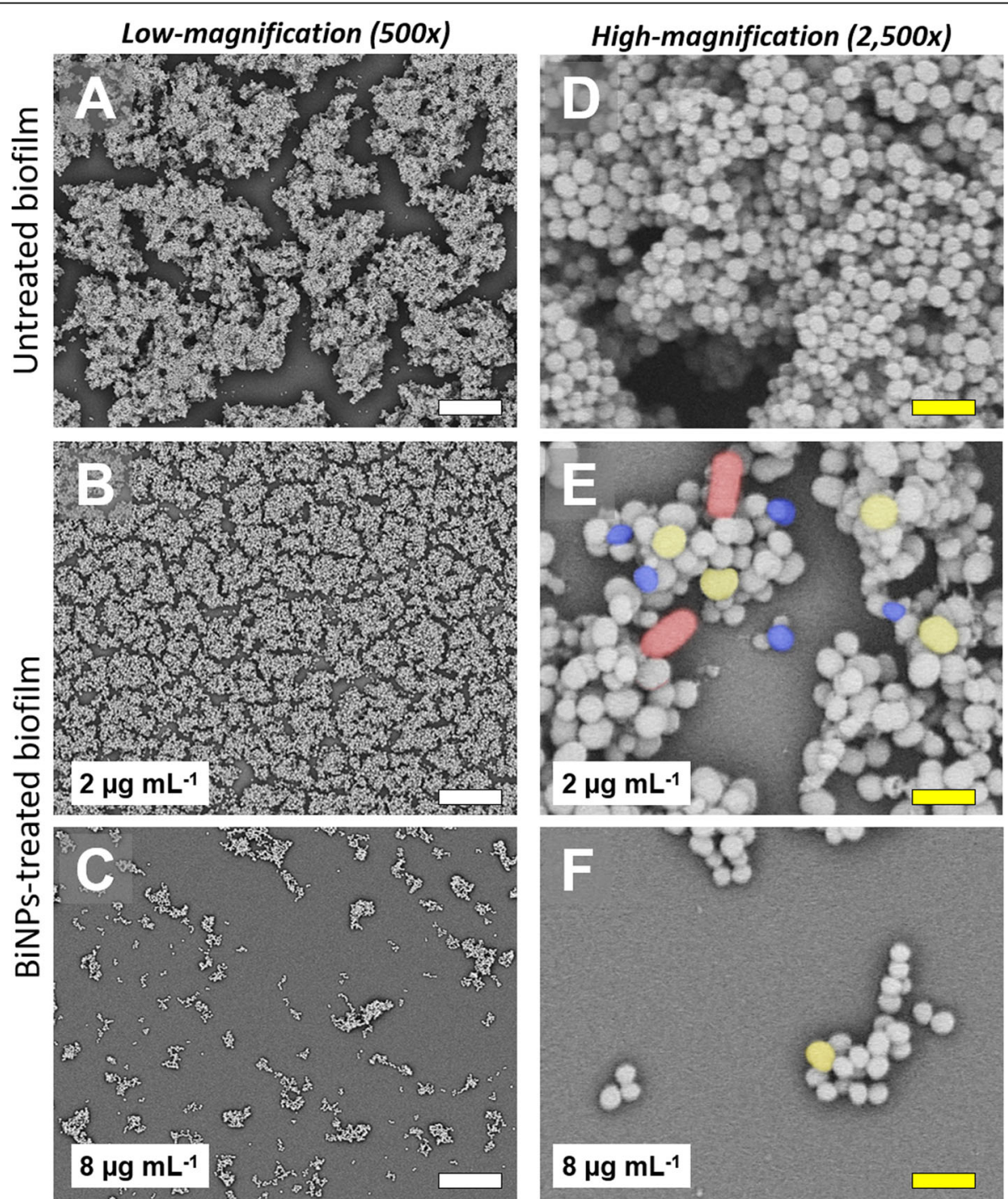

Fig. 5 BiNPs inhibit biofilm formation by S. aureus. Untreated controls (a, d), as well as BiNPs-treated samples exposed to a low concentration of nanoparticles (b), form biofilms, but the cells from on the BiNPs-treated samples, display changes in morphology (e), from changes in size (yellow and blue-colored cells), and in shape (red-colored cells). Samples treated with a higher concentration of BiNPs do not form biofilms, but the cell morphology changes were less common (f). Scale bars: white $=20 \mu \mathrm{m}$, yellow $=2 \mu \mathrm{m}$ 
Regarding the effect on C. albicans biofilms, SEM analysis confirmed that BiNPs negatively impact the dimorphic transition, from yeast to hyphae, and its ability to establish biofilms. On the untreated samples, lowmagnification images revealed thick biofilms with fullyformed hyphae that completely cover the surface (Fig. 6a). High-magnification images showed that only the hyphal shape is visible in the samples (Fig. 6d). Samples treated with sub-lethal concentrations of BiNPs $\left(4 \mu \mathrm{g} \mathrm{mL}^{-1}\right)$, also showed thick biofilms that totally covered the surface (Fig. 6b); however, alterations on the cell structure were evident. High-magnification images showed that yeast-like and pseudohyphae-like structures were abundant, confirming that BiNPs hinder the dimorphic transition ability of C. albicans (Fig. 6e). The impact of bismuth nanoparticles on the ability of C. albicans to form biofilms became more evident in samples treated with higher concentrations of BiNPs $(64 \mu \mathrm{g}$ $\left.\mathrm{mL}^{-1}\right)$. At this concentration, biofilm formation was greatly inhibited by the BiNPs, as seen in Fig. 6c, where only a few, aberrant-shaped hyphae were observable. The yeast-like and pseudohyphae-like structures also presented alterations on their morphology (Fig. 6f).

\section{Conclusion}

Our small, spheroid PVP-coated bismuth nanoparticles are more stable than the bismuth-BAL complex in aqueous solutions. Also, these BiNPs display antimicrobial

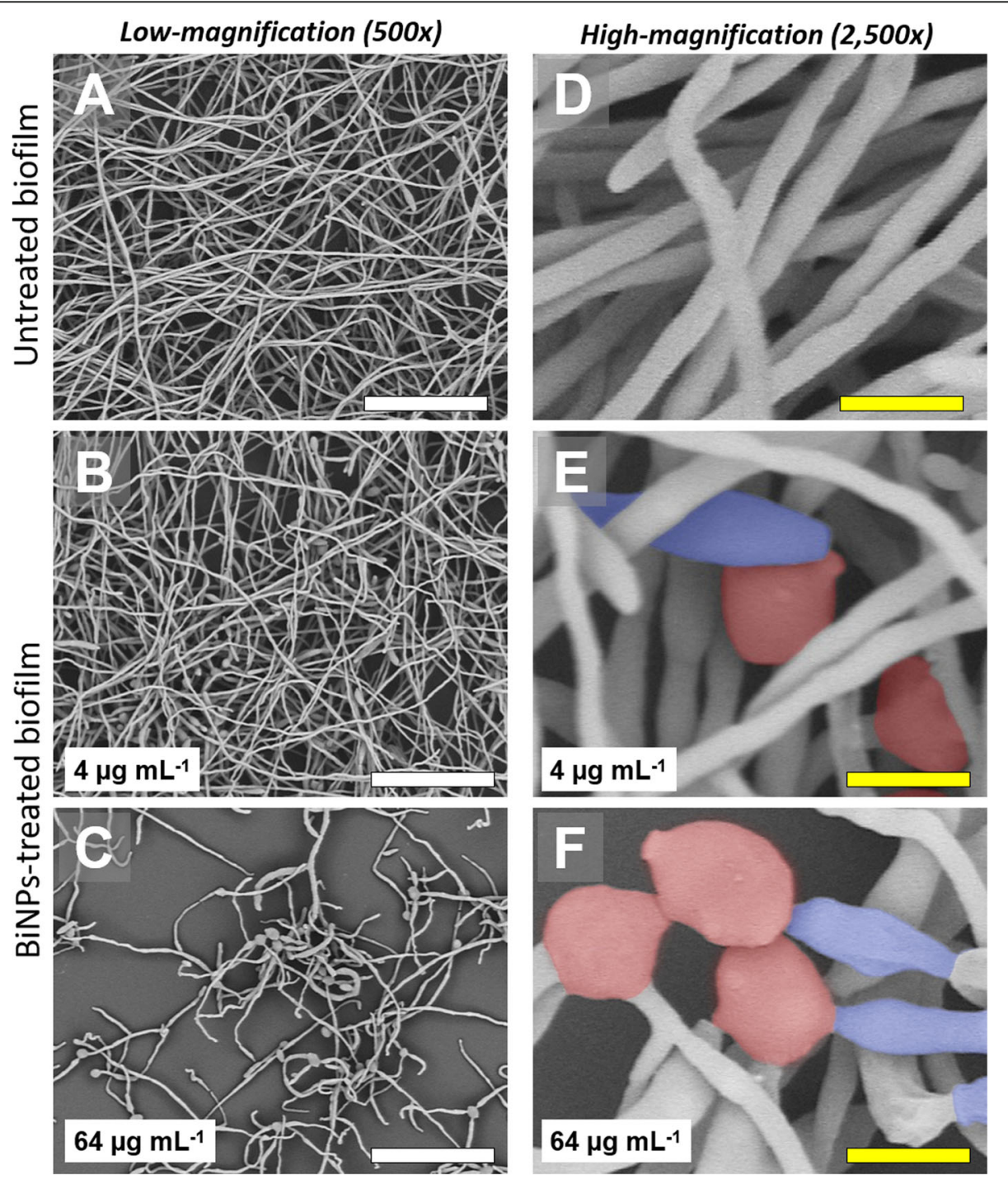

Fig. 6 BiNPs affect the dimorphic transition and inhibit biofilm formation in C. albicans. Untreated controls (a, d) show the typical filamentous C. albicans biofilms; however, in samples treated with a low concentration of BiNPs, the dimorphic transition is affected. $\mathbf{b}$, e In samples treated with a high concentration of BiNPs, biofilm formation is mostly inhibited, and the cells show aberrant morphologies (c, f). Yeast-like (in red) and pseudohyphae-like (in blue) cells were observed. Scale bars: white $=40 \mu \mathrm{m}$, yellow $=4 \mu \mathrm{m}$ 
activity against the bacterium $S$. aureus and the yeast $C$. albicans under both planktonic and biofilm formation stages. The antimicrobial activity of these BiNPs is comparable to or better than other BiNPs synthesized by more sophisticated methods. Moreover, the antimicrobial activity of the BiNPs is parallel to the commercially available antibiotics and is also similar in potency to that of silver nanoparticles. Microscopy analysis reveals that BiNPs reduce biofilm formation and negatively alter the cell morphology in both $S$. aureus and C. albicans. However, literature shows that bismuth nanoparticles may display cytotoxicity, therefore, more research regarding BiNPs biocompatibility and safety is needed for future applications. This work shows that cost-effective, fast, easy-to-synthesize nanomaterials may display broad antimicrobial activity against bacteria and fungi. These nanomaterials could be applied as broad-range sanitizers to decrease the dispersion of potential pathogenic cells and for reducing their ability to form biofilms in healthcare-related facilities and other public spaces.

\section{Supplementary information}

Supplementary information accompanies this paper at https://doi.org/10. 1186/s42490-020-00044-2.

Additional file 1: Fig. S1. TEM images confirms the presence of BiNPs. PVP-BiNPs display an aspect ratio close to 1 and the average size is below $10 \mathrm{~nm}$. Occasional other shapes and sizes are also observed. Fig. S2. Bismuth nanoparticles in aqueous solutions remain stable over time. Visual examination reveals that BiNPs remained stable over time. Visually, an 11week-old synthesis (B) kept light-protected at 4 oC, appears identical to a freshly prepared synthesis (A). UV-Vis spectrophotometry reveals that their optical properties (absorbance profiles) remain similar -with minor changes- (C) between the old synthesis (red) and the new preparation (blue). Fig. S3. Inhibition of S. aureus and C. albicans by different bismuth compounds under both planktonic and biofilm growing conditions. The dose-response curves against S. aureus (top panels), and C. albicans (bottom panels) show that bismuth compounds display different degrees of antimicrobial activity under planktonic (A, C) and biofilm (B, D) growing conditions. Lines: green (BiNPs), red (bismuth-BAL) and blue (Bi(NO3)3)

\section{Abbreviations}

PVP: Polyvinylpyrrolidone; BiNPs: Bismuth nanoparticles; MIC: Minimum Inhibitory Concentration; SEM: Scanning Electron Microscopy; BAL: British Anti-Lewisite; dimercaptopropanol.

\section{Acknowledgments}

The authors thank Dr. James Boyd, from the Department of Chemistry UTSA, for his support with the UV-Vis spectrophotometer; to the South Texas Center for Emerging Infectious Diseases (STCEID) for purchasing the SEM; and to the Graphic Designer Salma Carballo, for her assistance with the images.

\section{Authors' contributions}

RVM and JLLR designed the study; RVM and MJAJ performed the data acquisition; RVM, JLLR, and MJAJ contributed to the data analysis and interpretation; RVM drafted the work and JLLR, and MJAJ substantively revised it. The authors approved the submitted version.

\section{Funding}

RVM thanks the receipt of a postdoctoral scholarship from the CONACYT and the UTSA. Support in the laboratory was provided by the Margaret Batts

Tobin Foundation, San Antonio, TX, USA (to JLLR).

Availability of data and materials

Raw data from the "antimicrobial susceptibility assays" is available from the authors upon request.

Ethics approval and consent to participate

Not applicable.

Consent for publication

Not applicable.

\section{Competing interests}

The authors declare that there is no conflict of interest. The funders had no role in study design, data collection, data analysis, decision to publish, or preparation of the manuscript.

\section{Author details}

${ }^{1}$ The University of Texas at San Antonio, San Antonio, TX 78249, USA. ${ }^{2}$ The University of Texas at Dallas, Richardson, TX 75080, USA.

Received: 15 July 2020 Accepted: 8 September 2020

Published online: 14 October 2020

References

1. Ma L, Wu J, Wang S, Yang H, Liang D, Lu Z. Synergistic antibacterial effect of Bi2S3nanospheres combined with ineffective antibiotic gentamicin against methicillin-resistant Staphylococcus aureus. J Inorg Biochem. 2017; 168:38-45. https://doi.org/10.1016/j.jinorgbio.2016.12.005.

2. Sun H. Biological chemistry of arsenic, antimony and bismuth. Biological chemistry of arsenic, antimony and bismuth: Wiley; 2010. p. 383. [cited 2019 May 14]. Available from: https://books.google.com/books?hl=en\&lr=\&id= $n r K X C X Q F 0 Q A C \& o i=f n d \& p g=P R 13 \& d q=$ bismuth+uses\&ots=6_G0zPS5av\&sig= zzrYYe0psaPtazfOpyVktWbEwPw\#v=onepage\&q=bismuthuses\&f=false.

3. Badireddy AR, Hernandez-Delgadillo R, Sánchez-Nájera Rl, Chellam S, CabralRomero C. Synthesis and characterization of lipophilic bismuth dimercaptopropanol nanoparticles and their effects on oral microorganisms growth and biofilm formation. J Nanopart Res. 2014;16(6):2456. https://doi. org/10.1007/s11051-014-2456-5.

4. USGS. Bismuth statistics and information [internet]. National Minerals Information Center; 2019. [cited 2019 May 14]. Available from: https://www. usgs.gov/centers/nmic/bismuth-statistics-and-information.

5. Goldman RD. Bismuth salicylate for diarrhea in children. Can Fam Physician. 2013:59(8):843-4 [cited 2019 May 14]. Available from: http://www.ncbi.nlm. nih.gov/pubmed/23946025.

6. Kowalik M, Masternak J, Barszcz B. Recent research trends on bismuth compounds in cancer Chemoand radiotherapy. Curr Med Chem. 2019;26(4): 729-59 [cited 2019 Jun 27]. Available from: http://www.eurekaselect. com/156107/article

7. Cheng $Y$, Chang $Y$, Feng $Y$, Jian $H$, Tang Z, Zhang $H$. Deep-level defect enhanced Photothermal performance of bismuth sulfide-gold Heterojunction Nanorods for Photothermal therapy of cancer guided by computed tomography imaging. Angew Chem Int Ed. 2018;57(1):24651[cited 2019 Jun 27]. Available from. https://doi.org/10.1002/anie. 201710399.

8. Mahony DE, Lim-Morrison S, Bryden L, Faulkner G, Hoffman PS, Agocs L, et al. Antimicrobial activities of synthetic bismuth compounds against Clostridium difficile. Antimicrob Agents Chemother. 1999;43(3):582-8.

9. Ferraz KSO, Reis DC, Da Silva JG, Souza-Fagundes EM, Baran EJ, Beraldo H. Investigation on the bioactivities of clioquinol and its bismuth(III) and platinum(II, IV) complexes. Polyhedron. 2013;63:28-35. https://doi.org/10. 1016/j.poly.2013.07.008.

10. Folsom JP, Baker B, Stewart PS. In vitro efficacy of bismuth thiols against biofilms formed by bacteria isolated from human chronic wounds. J Appl Microbiol. 2011;111(4):989-96.

11. Domenico P, Salo RJ, Novick SG, Schoch PE, Van Horn K, Cunha BA Enhancement of bismuth antibacterial activity with lipophilic thiol chelators. 
Antimicrob Agents Chemother. 1997;41(8):1697-703 [cited 2019 Jun 28]. Available from: http://aac.asm.org/.

12. Varposhti, M.; Abdi Ali, A.; Mohammadi, P. Synergistic Effects of Bismuth Thiols and Various Antibiotics Against Pseudomonas aeruginosa Biofilm. Jundishapur J Microbiol. 2014;7:e9142. https://doi.org/10.5812/jjm.9142.

13. Warren SC, Jackson AC, Cater-Cyker ZD, Disalvo FJ, Wiesner U. Nanoparticle synthesis via the photochemical Polythiol process scheme 1. Synthetic route for the photochemical Polythiol process (metals tested include bismuth, copper, antimony, and Lead). J Am Chem Soc. 2007;129:35 [cited 2019 Aug 19]. Available from: http://pubs.acs.org.

14. Rudramurthy GR, Swamy MK, Sinniah UR, Ghasemzadeh A. Nanoparticles: alternatives against drug-resistant pathogenic microbes. Molecules. 2016; 21(7):1-30.

15. Phan HT, Haes AJ. What does nanoparticle stability mean? 2019. [cited 2020 Mar 30]; Available from: https://pubs.acs.org/sharingguidelines.

16. Tejamaya M, Römer I, Merrifield RC, Lead JR. Stability of citrate, PVP, and PEG coated silver nanoparticles in ecotoxicology media. Environ Sci Technol. 2012;46(13):7011-7. https://doi.org/10.1021/es2038596.

17. Auffan M, Achouak W, Rose J, Roncato MA, Chanéac C, Waite DT, et al. Relation between the redox state of iron-based nanoparticles and their cytotoxicity toward Escherichia coli. Environ Sci Technol. 2008;42(17):6730-5.

18. Edson JA, Kwon YJ. Design, challenge, and promise of stimuli-responsive nanoantibiotics. Nano Converg. 2016;3(1):26 Available from: http:// nanoconvergencejournal.springeropen.com/articles/10.1 186/s40580-016-0085-7.

19. Vazquez-Munoz R, Lopez-Ribot JL. Nanotechnology as an alternative to reduce the spread of COVID-19. Challenges. 2020;11(2):15 [cited 2020 Jun 25]. Available from: https://www.preprints.org/manuscript/202006.0301/v1.

20. Vance ME, Kuiken T, Vejerano EP, McGinnis SP, Hochella MF, Hull DR Nanotechnology in the real world: redeveloping the nanomaterial consumer products inventory. Beilstein J Nanotechnol. 2015;6(1):1769-80.

21. Weissig V, Pettinger TK, Murdock N. Nanopharmaceuticals (part 1): products on the market. Int J Nanomedicine. 2014;9:4357-73, https://doi.org/10.2147/ IJN.S46900.

22. Vega-Jiménez AL, Almaquer-Flores A, Flores-Castaneda M, Camps E, UribeRamirez M, Aztatzi-Aguilar OG, et al. Bismuth subsalicylate nanoparticles with anaerobic antibacterial activity for dental applications. Nanotechnology. 2017;28(43):435101 [cited 2019 May 8]. Available from: http://stacks.iop.org/0957-4484/28/i=43/a=435101?key=crossref.8fa78a002e2 fc7137c89f3dcbf899d1a.

23. Esmaeillou M, Zarrini G, Ahangarzadeh Rezaee M, Shahbazi Mojarrad J, Bahadori A. Vancomycin capped with silver nanoparticles as an antibacterial agent against multi-drug resistance bacteria. Adv Pharm Bull. 2017;7(3):47983 [cited 2019 Apr 6]. Available from: http://www.ncbi.nlm.nih.gov/ pubmed/29071232.

24. El-Batal Al, El-Sayyad GS, El-Ghamry A, Agaypi KM, Elsayed MA, Gobara M. Melanin-gamma rays assistants for bismuth oxide nanoparticles synthesis at room temperature for enhancing antimicrobial, and photocatalytic activity. J Photochem Photobiol B Biol. 2017;173(April):120-39. https://doi.org/10.1016/ j.jphotobiol.2017.05.030.

25. Reus TL, Machado TN, Bezerra AG, Marcon BH, Paschoal ACC, Kuligovski C, et al. Dose-dependent cytotoxicity of bismuth nanoparticles produced by LASiS in a reference mammalian cell line BALB/C 3T3. Toxicol In Vitro. 2018; 53:99-106 [cited 2019 Jun 27]. Available from: https://www.sciencedirect. com/science/article/pii/S0887233318303473?via\%3Dihub.

26. Gomez C, Hallot G, Pastor A, Laurent S, Brun E, Sicard-Roselli C, et al. Metallic bismuth nanoparticles: towards a robust, productive and ultrasound assisted synthesis from batch to flow-continuous chemistry. Ultrason Sonochem. 2019:56:167-73 [cited 2019 Jun 27]. Available from: https:// www.sciencedirect.com/science/article/pii/S1350417718314809?via\%3Dihub.

27. Bi $H$, He F, Dong $Y$, Yang D, Dai $Y$, Xu $L$, et al. Bismuth nanoparticles with "light" property served as a multifunctional probe for $X$-ray computed tomography and fluorescence imaging. Chem Mater. 2018;30(10):3301-7 [cited 2019 Jun 27]. Available from: http://pubs.acs.org/doi/10.1021/acs. chemmater.8b00565.

28. Winter H, Christopher-Allison E, Brown AL, Goforth AM. Aerobic method for the synthesis of nearly size-monodisperse bismuth nanoparticles from a redox non-innocent precursor. Nanotechnology. 2018;29(15):155603 [cited 2019 Jun 27]. Available from: http://stacks.iop.org/0957-4484/29/i=15/a= 155603?key=crossref.9ee7a59673ed4badf489622fb2292fee.
29. Wei B, Zhang X, Zhang C, Jiang Y, Fu YY, Yu C, et al. Facile synthesis of uniform-sized bismuth nanoparticles for $C T$ visualization of gastrointestinal tract in vivo. ACS Appl Mater Interfaces. 2016;8(20):12720-6.

30. Pietro RA, Varbanov PS, Lauciello S, Salerno M, Fabiano B. An eco-friendly process for zerovalent bismuth nanoparticles synthesis. J Clean Prod. 2018; 198:37-45 [cited 2019 Jun 27]. Available from: https://www.sciencedirect. com/science/article/pii/S0959652618319784?via\%3Dihub.

31. Shakibaie M, Amiri-Moghadam P, Ghazanfari M, Adeli-Sardou M, Jafari M, Forootanfar H. Cytotoxic and antioxidant activity of the biogenic bismuth nanoparticles produced by Delftia sp. SFG. Mater Res Bull. 2018;104:155-63 [cited 2019 Jun 27]. Available from: https://www.sciencedirect.com/science/ article/pii/S0025540817318536?via\%3Dihub.

32. Nazari P, Faramarzi MA, Sepehrizadeh Z, Mofid MR, Bazaz RD, Shahverdi AR. Biosynthesis of bismuth nanoparticles using Serratia marcescens isolated from the Caspian Sea and their characterisation. IET Nanobiotechnol. 2012; 6(2):58 [cited 2019 Jun 27]. Available from: https://digital-library.theiet.org/ content/journals/10.1049/iet-nbt.2010.0043.

33. Vazquez-Munoz R, Arellano-Jimenez MJ, Lopez-Ribot JL. Fast, facile synthesis method for BAL-mediated PVP-bismuth nanoparticles. MethodsX. 2020;7: 100894 [cited 2020 Apr 19]. Available from: https://linkinghub.elsevier.com/ retrieve/pii/S2215016120301138.

34. CLSI. M07. In: Weinstein MP, editor. Methods for dilution antimicrobial susceptibility tests for bacteria that grow aerobically. 11th ed. Wayne; 2018. Available from: https://clsi.org/standards/products/microbiology/ documents/m07/.

35. CLSI. M27. In: Alexander BD, editor. Reference method for broth dilution antifungal susceptibility testing of yeasts. 4th ed. Wayne: Clinical Laboratory Standards Institute; 2017. Available from: https://clsi.org/standards/products/ microbiology/documents/m27/.

36. Torres NS, Abercrombie JJ, Srinivasan A, Lopez-Ribot JL, Ramasubramanian AK, Leung KP. Screening a commercial library of pharmacologically active small molecules against Staphylococcus aureus biofilms. Antimicrob Agents Chemother. 2016;60(10):5663-72 Available from: http://aac.asm.org/lookup/ doi/10.1128/AAC.00377-16.

37. Montelongo-Jauregui D, Srinivasan A, Ramasubramanian AK, Lopez-Ribot JL. An in vitro model for oral mixed biofilms of Candida albicans and Streptococcus gordonii in synthetic saliva. Front Microbiol. 2016;7(MAY):1-13.

38. Pierce CG, Uppuluri P, Tristan AR, Wormley FL, Mowat E, Ramage G, et al. A simple and reproducible 96-well plate-based method for the formation of fungal biofilms and its application to antifungal susceptibility testing. Nat Protoc. 2008;3(9):1494-500.

39. Gomez C, Hallot G, Port M. Bismuth metallic nanoparticles. In: Inorganic frameworks as smart Nanomedicines: Elsevier; 2018. p. 449-87. https://doi. org/10.1016/B978-0-12-813661-4.00010-9.

40. Baset S, Akbari H, Zeynali H, Shafie M. Size measurement of metal and semiconductor nanoparticles via UV-Vis absorption spectra. Dig J Nanomater Biostruct. 2011;6(2):709-16.

41. Li J, Fan H, Chen J, Liu L. Synthesis and characterization of poly(vinyl pyrrolidone)-capped bismuth nanospheres. Colloids Surfaces A Physicochem Eng Asp. 2009;340(1-3):66-9.

42. Wang YW. Hong $\mathrm{H}$, Kim KS. Size control of semimetal bismuth nanoparticles and the UV-visible and IR absorption spectra; 2005. [cited 2019 May 29]; Available from: https://pubs.acs.org/doi/10.1021/jp046423v.

43. Ma D, Zhao J, Li Y, Su X, Hou S, Zhao Y, et al. Organic molecule directed synthesis of bismuth nanostructures with varied shapes in aqueous solution and their optical characterization. Colloids Surfaces A Physicochem Eng Asp. 2010;368(1-3):105-11. https://doi.org/10.1016/j.colsurfa.2010.07.022.

44. Xia F, Xu X, Li X, Zhang L, Zhang L, Qiu H, et al. Preparation of bismuth nanoparticles in aqueous solution and its catalytic performance for the reduction of 4-Nitrophenol. Ind Eng Chem Res. 2014;53:28 [cited 2020 Aug 24]. Available from: https://pubs.acs.org/sharingguidelines.

45. Tejamaya M, Römer I, Merrifield RC, Lead JR. Stability of citrate, PVP, and PEG coated silver nanoparticles in ecotoxicology media. Environ Sci Technol. 2012;46(13):7011-7.

46. Rogero SO, Malmonge SM, Lugão AB, Ikeda TI, Miyamaru L, Cruz ÁS. Biocompatibility study of polymeric biomaterials. Artif Organs. 2003;27(5): 424-7[cited 2019 Jul 12]. Available from. https://doi.org/10.1046/j.1525-1594. 2003.07249.x.

47. Koczkur KM, Mourdikoudis S, Polavarapu L, Skrabalak SE. Polyvinylpyrrolidone (PVP) in nanoparticle synthesis. Dalton Trans. 2015; 
44(41):17883-905 [cited 2019 Jul 15]. Available from: http://xlink.rsc.org/ ?DOI=C5DT02964C

48. Brown AL, Goforth AM. PH-dependent synthesis and stability of aqueous, elemental bismuth glyconanoparticle colloids: potentially biocompatible Xray contrast agents. Chem Mater. 2012;24(9):1599-605.

49. Wang F, Tang R, Yu H, Gibbons PC, Buhro WE. Size- and shape-controlled synthesis of bismuth nanoparticles. Chem Mater. 2008;20(11):3656-62 Available from: http://pubs.acs.org/doi/abs/10.1021/cm8004425.

50. Borovikova LN, Polyakova IV, Korotkikh EM, Lavrent'ev VK, Kipper Al, Pisarev OA. Synthesis and stabilization of bismuth nanoparticles in aqueous solutions. Russ J Phys Chem A. 2018;92(11):2253-6 [cited 2019 Jun 27]. Available from: http://link.springer.com/10.1134/S0036024418110055.

51. Luz A, Feldmann C. Reversible photochromic effect and electrochemical voltage driven by light-induced Bio-formation. J Mater Chem. 2009;19(43): 8107 [cited 2019 Aug 19]. Available from: http://xlink.rsc.org/?DOl=b907146f.

52. Firouzi Dalvand L, Hosseini F, Moradi Dehaghi S, Siasi Torbati E. Inhibitory effect of bismuth oxide nanoparticles produced by bacillus licheniformis on methicillin-resistant Staphylococcus aureus strains (MRSA). Iran J Biotechnol. 2018;16(4):279-86 [cited 2019 May 8]. Available from: http://www.ijbiotech. com/article_80169.html.

53. Meeker DG, Beenken KE, Mills WB, Loughran AJ, Spencer HJ, Lynn WB, et al. Evaluation of antibiotics active against methicillin-resistant Staphylococcus aureus based on activity in an established biofilm; 2016. [cited 2020 Feb 24]; Available from: http://aac.asm.org/.

54. Vazquez-Muñoz R, Arellano-Jimenez MJ, Lopez FD, Lopez-Ribot UL. Protocol optimization for a fast, simple and economical chemical reduction synthesis of antimicrobial silver nanoparticles in non-specialized facilities. BMC Res Notes. 2019;12(1):773 Available from: https://bmcresnotes.biomedcentral. com/articles/10.1186/s13104-019-4813-z.

55. Baek YW, An YJ. Microbial toxicity of metal oxide nanoparticles (CuO, NiO, $\mathrm{ZnO}$, and Sb2O3) to Escherichia coli, Bacillus subtilis, and Streptococcus aureus. Sci Total Environ. 2011:409(8):1603-8.

56. Shrestha SK, Fosso MY, Garneau-Tsodikova S. A combination approach to treating fungal infections. Sci Rep. 2015;23:5.

57. Rautemaa R, Richardson M, Pfaller MA, Perheentupa J, Saxén H. Activity of amphotericin B, anidulafungin, caspofungin, micafungin, posaconazole, and voriconazole against Candida albicans with decreased susceptibility to fluconazole from APECED patients on long-term azole treatment of chronic mucocutaneous candidiasis. Diagn Microbiol Infect Dis. 2008;62(2):182-5 Available from: https://inkinghub.elsevier.com/retrieve/pii/S07328893 08002630.

58. Padmavathi AR, Murthy SS, Das A, Priya A, Sushmitha TJ, Pandian SK, et al. Impediment to growth and yeast-to-hyphae transition in Candida albicans by copper oxide nanoparticles. Biofouling. 2020;36(1):56-72 [cited 2020 Aug 24]. Available from: https://www.tandfonline.com/doi/full/10.1080/0892 7014.2020.1715371.

59. Badireddy AR, Marinakos SM, Chellam S, Wiesner MR. Lipophilic nanobismuth inhibits bacterial growth, attachment, and biofilm formation. Surf Innov. 2013;1(3):181-9.

60. Hernandez-Delgadillo R, Del Angel-Mosqueda C, Solís-Soto JM, MunguiaMoreno S, Pineda-Aguilar N, Sánchez-Nájera Rl, et al. Antimicrobial and antibiofilm activities of MTA supplemented with bismuth lipophilic nanoparticles. Dent Mater J. 2017;36(4):503-10 [cited 2019 Aug 26]. Available from: https://www.jstage.jst.go.jp/article/dmj/36/4/36_2016-259/_article.

61. Goswami SR, Sahareen T, Singh M, Kumar S. Role of biogenic silver nanoparticles in disruption of cell-cell adhesion in Staphylococcus aureus and Escherichia coli biofilm. J Ind Eng Chem. 2015;26:73-80 [cited 2019 Mar 24]. Available from: https://www.sciencedirect.com/science/article/pii/S1226 086X14005711?via\%3Dihub\#bib0310.

62. Cirioni O, Giacometti A, Ghiselli R, Bergnach C, Orlando F, Mocchegiani F, et al. Pre-treatment of central venous catheters with the cathelicidin BMAP-28 enhances the efficacy of antistaphylococcal agents in the treatment of experimental catheter-related infection. Peptides. 2006;27(9):2104-10 Available from: https://linkinghub.elsevier.com/retrieve/pii/S0196978106001094.

63. Hernandez-Delgadillo R, Velasco-Arias D, Martinez-Sanmiguel JJ, Diaz D, Zumeta-Dube I, Arevalo-Niño K, et al. Bismuth oxide aqueous colloidal nanoparticles inhibit Candida albicans growth and biofilm formation. Int J Nanomedicine. 2013:8:1645-52.

64. Lara HH, Romero-Urbina DG, Pierce C, Lopez-Ribot JL, Arellano-Jiménez MJ, Jose-Yacaman M. Effect of silver nanoparticles on Candida albicans biofilms: An ultrastructural study. J Nanobiotechnology. 2015;13(1):1-12.
65. Nadhe SB, Singh R, Wadhwani SA, Chopade BA. Acinetobacter sp. mediated synthesis of AgNPs, its optimization, characterization and synergistic antifungal activity against C. albicans. J Appl Microbiol. 2019;127(2):445-58 [cited 2019 Sep 5]. Available from: https://onlinelibrary.wiley.com/doi/abs/1 $0.1111 / \mathrm{jam} .14305$

66. Nett JE, Crawford K, Marchillo K, Andes DR. Role of Fks1p and matrix glucan in Candida albicans biofilm resistance to an echinocandin, pyrimidine, and polyene. Antimicrob Agents Chemother. 2010;54(8):3505-8.

67. Domenico P, Baldassarri L, Schoch PE, Kaehler K, Sasatsu M, Cunha BA. Activities of bismuth thiols against staphylococci and staphylococcal biofilms. Antimicrob Agents Chemother. 2001 May 1;45(5):1417-21.

68. Sadler PJ, Li H, Sun H. Coordination chemistry of metals in medicine: target sites for bismuth. Coord Chem Rev. 1999 May 1;185-186:689-709.

69. Chen Z, Zhou Q, Ge R. Inhibition of fumarase by bismuth(III): implications for the tricarboxylic acid cycle as a potential target of bismuth drugs in helicobacter pylori. BioMetals. 2012;25(1):95-102 [cited 2019 Jun 28]. Available from: http://link.springer.com/10.1007/s10534-011-9485-7.

70. Beatrix Bialek FT, Bialek B, Hensel R. Medical use of bismuth: the two sides of the coin. J Clin Toxicol. 2011;s3(01):1-5 [cited 2019 Jun 28]. Available from: https://www.omicsonline.org/medical-use-of-bismuth-the-two-sidesof-the-coin-2161-0495.S3-004.php?aid=5343.

\section{Publisher's Note}

Springer Nature remains neutral with regard to jurisdictional claims in published maps and institutional affiliations.
Ready to submit your research? Choose BMC and benefit from:

- fast, convenient online submission

- thorough peer review by experienced researchers in your field

- rapid publication on acceptance

- support for research data, including large and complex data types

- gold Open Access which fosters wider collaboration and increased citations

- maximum visibility for your research: over $100 \mathrm{M}$ website views per year

At BMC, research is always in progress.

Learn more biomedcentral.com/submissions 